possibility of lung or heart and lung transplants in adequately selected cases. The selection of candidates for the transplant programme is crucial for their long term survival, and should include careful monitoring of renal function and signs of renal damage, particularly proteinuria. The patients now admitted to transplant programmes are generally in advanced stages of the disease when secondary complications are more probable. It is very important to exclude the presence of amyloidosis in these subjects. In our opinion, even the mild and occasional proteinuria that is sometimes observed in cystic fibrosis children merits particular attention, with the aim of promptly identifying patients at risk of progressively severe renal impairment and of prescribing appropriate treatments to prevent or at least delay severe clinical manifestations.

1 Abramowsky CR, Swinehart GL. The nephropathy of cystic fibrosis: a human model of chronic nephrotoxicity. Hum Pathol 1982;13:934-9.

2 Katz SM, Krueger LJ, Falkner B. Microscopic nephrocalcinosis in cystic fibrosis. $N$ Engl f Med 1988;319:263-6.

3 Ristow SC, Condemi JJ, Stuart ID, Schwartz RH, Bryson MF. Systemic amyloidosis in cystic fibrosis. Am $\mathcal{F}$ Dis Child 1977;131:886-8.

4 Canciani M, Pederzini F, Mastella G, Boccato P. Systemic amyloidosis in cystic fibrosis. Acta Paediatr Scand 1985;74: 613-4.

5 Rifai A, Millard K. Glomerular deposition of immune complexes prepared with monomeric or polymeric IgA. Clin Exp Immunol 1985;60:363-8.

6 Coppo R, Basolo B, Martina G, et al. Circulating immune complexes containing IgA, IgG and IgM in patients with primary IgA and with Henoch-Schönlein nephritis: correlation with clinical and histologic signs of activity. Clin Nephrol 1982;18:230-9.

\title{
Nutritional manipulation in the management of dumping syndrome
}

Department of Pediatrics, Division of GI and Nutrition, Louisiana State University Medical Center, New Orleans, USA

Vikram Khoshoo

Departments of

Paediatrics and

Nutritional Sciences,

University of Toronto,

Division of Clinical

Nutrition

Paul B Pencharz

\section{Division of}

Gastroenterology

Ram M Reifen

Ben D Gold

Philip M Sherman

Correspondence to:

Professor Paul Pencharz,

Division of Clinical Nutrition,

The Hospital for

Sick Children

555 University Avenue,

Toronto, Ontario,

Accepted 15 August 1991

(Arch Dis Child 1991;66:1447-8)

Vikram Khoshoo, Ram M Reifen, Ben D Gold, Philip M Sherman, Paul B Pencharz

\begin{abstract}
Two children with Nissen's fundoplication and either gastrocystoplasty or pyloroplasty developed dumping syndrome. Correction of their blood glucose abnormalities, resolution of symptoms, and weight gain were effectively achieved by addition of fats and uncooked corn starch $(50 \mathrm{~g} / \mathrm{l})$ to their feeds.
\end{abstract}

There is a paucity of literature regarding the prevalence and optimal management of dumping syndrome in children. This results from the rapid gastric emptying of a carbohydrate meal, causing hyperglycaemia followed by reactive, symptomatic hypoglycaemia. Dumping syndrome in children has been described almost exclusively as a postoperative complication of Nissen's fundoplication. ${ }^{1-3}$ Several therapeutic approaches have been tried with mixed results: for example, continuous nasogastric or gastrostomy feeds, frequent small amounts of thickened feeds and the addition of complex carbohydrates such as fibre and uncooked corn starch. ${ }^{45}$ We report on two children treated by a combination of complex carbohydrate and fats to delay gastric emptying and provide a stable release of glucose, leading to normoglycaemia and amelioration of symptoms.

\section{Case reports}

CASE 1

At 10 months of age this girl underwent bladder augmentation using gastric mucosa (that is, gastrocystoplasty) for treatment of reflux nephropathy. At 15 months of age she had further bladder augmentation with ileocystoplasty and an antireflux procedure (Nissen's fundoplication) for clinically and radiologically significant gastro-oesophageal reflux. At 17 months (two months after surgery) she was readmitted for evaluation of persisting diarrhoea and food aversion. On specific questioning her parents reported that she also had acute abdominal discomfort and lethargy after meals, accompanied by pallor and sweating.

In hospital, a brief tonic-clonic seizure occurred postprandially. At that time she was found to be hypoglycaemic $(1.5 \mathrm{mmol} / \mathrm{l})$ and required correction with a glucose infusion. No other metabolic abnormality was detected. A computed tomographic scan of the brain and an electroencephalogram were both normal. Subsequently, in the hospital, an oral glucose tolerance test $(2 \mathrm{~g} / \mathrm{kg}$ glucose) was performed which showed an initial hyperglycaemic response (blood glucose concentration, $7 \cdot 8 \mathrm{mmol} / \mathrm{l}$ at 30 min) followed by hypoglycaemia (blood glucose 3.5 and $2.1 \mathrm{mmol} / \mathrm{l}$ at 45 and $60 \mathrm{~min}$, respectively). Barium swallow showed a normal oesophagus, microgastria, and rapid stomach emptying. The latter was confirmed by a gastric emptying scan with ${ }^{99 m}$ Tc-labelled sulphur colloid which showed no gastric residue at 30 minutes. A diagnosis of dumping syndrome was made and she was placed on frequent small feeds and the addition of corn oil. This alleviated the postprandial glucose abnormalities totally and clinical symptoms partially.

Two months later she was readmitted for continued symptoms relating to the dumping syndrome, including irritability, worsening food aversion, and slow weight gain. She was stabilised with continuous nasogastric feeding (Similac PM 60/40, Ross Laboratories). In an attempt to wean her to bolus feeds during the daytime hours, a safflower oil based fat emulsion (Microlipid 50\%, Sherwood Medical Industries) was added to her formula feeds to delay gastric emptying but without any success. Subsequently, uncooked corn starch was added to her 
formula feeds at a concentration of $50 \mathrm{~g} / \mathrm{l}$. Symptoms improved markedly and her blood glucose concentration remained stable throughout the interval between feeds $(4 \cdot 3-5 \cdot 6 \mathrm{mmol} / \mathrm{l})$. Gradually, nasogastric feedings were changed to three bolus feeds during the day and a 10 hours' overnight continuous infusion. On this regimen her mood improved dramatically, weight increased by $2100 \mathrm{~g}$ over the next 140 days, and she began to take small amounts of food by mouth. She is now 23 months old.

CASE 2

This 4 year old boy had a history of accidental ingestion of caustic drain cleaner and subsequent development of strictures in the oesophagus, antrum, glottis, and supraglottis. He underwent a tracheotomy and subsequently a feeding gastrostomy, Nissen's fundoplication, and pyloroplasty. Six months after the operation his mother reported that he was experiencing discomfort during and after gastrostomy bolus feeds. After a clinical diagnosis of delayed gastric emptying he was prescribed metoclopramide. His symptoms worsened considerably and he was admitted to hospital.

He was found to have episodes of tachycardia, sweating, and pallor immediately after feeds. His symptoms were worse after the daytime bolus feeds and he had, by himself, adopted a left lateral position during and after feeds to experience some relief of symptoms. He was clinically diagnosed to have 'intolerance' to feeds and his feeds were diluted to 0.75 strength Isosource (Sandoz Canada), an iso-osmolar, $4.18 \mathrm{~kJ}(1 \mathrm{kcal}) / \mathrm{ml}$, casein-soy based tube feeding formula. Additional energy was supplied by medium chain triglycerides (MCT Oil, Mead Johnson). This dietary manipulation provided some relief of symptoms.

At this stage he was clinically diagnosed to have dumping syndrome which was confirmed as in the first case. His blood glucose concentration at 30 minutes after a $2 \mathrm{~g} / \mathrm{kg}$ glucose load was $10.0 \mathrm{mmol} / \mathrm{l}$, which dropped to $2.0 \mathrm{mmol} / \mathrm{l}$ at 90 min with marked symptoms. His feeds were changed to $940 \mathrm{ml}$ of Isosource with $90 \mathrm{ml}$ $50 \%$ Microlipid, $40 \mathrm{~g}$ uncooked corn starch, and $440 \mathrm{ml}$ water, which provided $334.4 \mathrm{~kJ} / \mathrm{kg} /$ day and $1.8 \mathrm{~g} / \mathrm{kg} /$ day of protein. The feeds were initially given as three bolus feeds during the day with 12 hour continuous drip at night and subsequently changed to 2 daytime bolus feeds of $375 \mathrm{ml}$ each and nine hour continuous feed at night. This was accompanied by a considerable improvement in postprandial blood glucose and symptoms. The amount of corn starch was increased to $70 \mathrm{~g}$ in the feeds (about $50 \mathrm{~g} / \mathrm{l}$ ) which resulted in further resolution of symptoms.

\section{Discussion}

These two cases illustrate the occurrence of dumping syndrome after two different gastrointestinal surgical procedures, along with Nissen's fundoplication: that is, gastrocystoplasty and pyloroplasty. Both the patients presented with considerable symptoms and failure to thrive, a major component of which was learned aversion to food as in the study by Hirsig et al. ${ }^{2}$ In both cases, effective control of symptoms and nutritional rehabilitation was achieved by dietary manipulations alone. Nutritional management was designed in accordance with the underlying altered physiology. Fats were used to delay gastric emptying and uncooked corn starch was used to deliver small amounts of glucose at a steady rate over a relatively longer time period. The latter has been used previously in the management of hypoglycaemia associated with type I glycogen storage disease. ${ }^{6}$

Microlipid was chosen as the fat source for several reasons. Firstly, it is a commercially available fat emulsion that is readily miscible in a liquid phase and thus it is appropriate for use in tube feeding. Secondly, as Microlipid is composed of long chain triglycerides, it will delay the gastric emptying more than medium chain triglycerides. Microlipid also provides a nutritionally balanced fat source with essential fatty acids. The choice of uncooked corn starch was based on several factors: it produces a slow and sustained blood glucose concentration; other commonly used and commercially available glucose polymers (for example, Polycose, Ross Laboratories) have a shorter chain length and produce a sharper and less sustained blood glucose response; corn starch can be used as a bolus and it eliminates the need to use continuous feeding; and finally it is easily available an inexpensive.

The management of dumping syndrome should be aimed at resolving clinical symptoms and improving nutrition simultaneously. This can be effectively achieved by the methods outlined.

1 Meyer S, Deckelbaum RJ, Lax E, et al. Infant dumping syndrome after gastroesophageal surgery. $\mathcal{F}$ Pediatr 1981 99:235-7.

2 Hirsig J, Baals H. Tuchschmid P, Spitz L, Stauffer UG Dumping syndrome following Nissen's fundoplication: cause for refusal to feed. 7 Pediatr Surg 1984;19:155-7.

3 Caulfield ME, Wyllie R, Firor HV, Michener W. Dumping syndrome in children. $\mathcal{F}$ Pediatr 1987;110:212-5.

4 Gitzelmann R, Hirsig J. Infant dumping syndrome: reversa of symptoms by feeding uncooked corn starch. Eur Pediatr 1986; 145:504-6.

5 Kneepkens CMF, Fernandes J, Vonk RJ. Dumping syndrome in children. Acta Paediatr Scand 1988;77:279-86.

6 Chen YT, Cornblath M, Sidbury JB. Cornstarch therapy in type I glycogen-storage disease. N Engl f Med 1984;310: 